\title{
Clinical Analysis of High Resolution Manometry (HRM) in Patients with Laryngopharyngeal Reflux Disease
}

\author{
Je Yeon Lee, Ryung Chae, Seok Jin Hong, Sang Hyuk Lee and Sung Min Jin \\ Department of Otolaryngology-Head and Neck Surgery, Kangbuk Samsung Hospital, Sungkyunkwan University School of Medicine, \\ Seoul, Korea
}

인후두 역류질환 환자에서 고해상도 식도내압검사 분석

이제연 · 채 령 · 홍석진 · 이상혁 · 진성민

성균관대학교 의과대학 강북삼성병원 이비인후과교실

\author{
Received June 4, 2013 \\ Revised August 6, 2013 \\ Accepted August 16, 2013 \\ Address for correspondence \\ Sang Hyuk Lee, MD \\ Department of Otolaryngology- \\ Head and Neck Surgery, \\ Kangbuk Samsung Hospital, \\ Sungkyunkwan University \\ School of Medicine, \\ 29 Saemunan-ro, Jongno-gu, \\ Seoul 110-746, Korea \\ Tel $+82-2-2001-1924$ \\ Fax $+82-2-2001-2273$ \\ E-mail entlsh@hanmail.net
}

Background and Objectives High resolution manometry (HRM), a newly developed device that uses 36 channels to plot pressure topography of esophagus, has recently been applied to evaluate the esophageal and upper esophageal sphincter (UES) status; however, its definite role in laryngopharyngeal reflux disease (LPRD) is not well elucidated. The aim of this study was to evaluate clinical usefulness of HRM and to elucidate the association between HRM findings and dysphasia in LPRD patients.

Subjects and Method A total of 56 patients who had been diagnosed LPRD from July 2010 to July 2011 were prospectively enrolled in this study. Patients consisted of 20 men and 36 women, with the mean age of 51.4 years. Every patient performed the questionnaire and HRM examination. A comparative analysis was performed to evaluate the correlation between the HRM results and LPRD.

Results Of 30 patients $(53.6 \%)$, there were 11 peristaltic dysfunction $(19.7 \%), 6$ relaxation impairment of lower esophageal sphincter (LES)(10.7\%), 4 diffuse esophageal spasm (7.1\%), 4 hypotensive LES (7.1\%), 3 Nutcracker esophagus (5.4\%), and 2 relaxation impairment of UES (3.6\%). The mean distance of UES from the nostril was $17.88 \pm 2.17 \mathrm{~cm}$ and the mean UES basal pressure was $63.10 \pm 24.49 \mathrm{~mm} \mathrm{Hg}$. Differences between the prevalence of abnormal findings shown by HRM and dysphasia symptoms were not statistically significant.

Conclusion In this study, a considerable amount of abnormalities in esophageal function were observed using HRM, and thus we think that HRM could provide useful information about esophagus dysfunction in LPRD patients.

Korean J Otorhinolaryngol-Head Neck Surg 2013;56:637-41

Key Words Diagnosis - Esophagus - Laryngopharyngeal reflux disease - Manometry · Symptom.

\section{서 론}

인후두 역류질환(laryngopharyngeal reflux disease)은 이비인후과에서 비교적 흔히 볼 수 있는 질환으로 후두 이물 감, 만성적인 기침, 애성과 같은 비특이적인 증상을 보인다.1,2) 진단에는 후두 내시경, 위 내시경, 식도 조영술, 식도내압검사 및 이중 탐침 24시간 산도 검사 등이 이용되지만, 아직 객관적
이고 정확한 진단방법은 정립되어 있지 않다. 기립시에도 증상 이 나타나는 등 위식도 역류질환과는 다른 병태생리를 보이며, 치료약물로서는 제산제, $\mathrm{H}_{2}$ 수용체 차단제, 위장관 운동 촉진 제, 양성자 펌프 억제제 등이 사용된다. ${ }^{3,4)}$

식도내압검사(manometry)는 식도 내부 및 괄약근의 압력 을 측정하고 식도 기능에 대한 근신경 활성도 등을 알 수 있는 검사이다. ${ }^{5)}$ 기존의 식도내압검사는 사용되는 도관이 굵어서 검 
사시 환자의 불편감을 많이 유발하고, 검사도관의 센서 수가 적고 간격이 넓어 특정 부위의 결과를 얻기 힘든 단점이 있었 다. ${ }^{5)}$ 최근 기구와 장비의 많은 발전으로 고해상도 식도내압검 사가 임상에서 사용되고 있는데, 이 검사는 $4 \mathrm{~mm}$ 정도의 얇은 도관을 사용하여 검사시 환자의 순응도를 많이 향상시켰고, 도관의 채널이 36 개, 채널당 센서가 12 개로 늘어나고, 식도의 압력 변화를 정량 지형분석을 통한 색상의 변화로 표현하여 구체적이고 정확한 결과를 얻게 되었다. ${ }^{6.7)}$ 이와 같이 고해상도 식도내압검사는 기존의 검사와 비교하여 많은 채널과 센서를 이용하고 압력의 변화를 색상의 변화로 표현하여 비교적 쉽 고 정확하게 특정부위 식도의 기능을 측정할 수 있는 장점이 있다.

최근 위식도 역류질환(gastroesophageal reflux disease)에 서 고해상도 식도내압검사를 적용하였을 때 $66.4 \%$ 의 환자에 서 식도의 운동장애가 확인되었다는 보고가 있으며," 또한 고 해상도 식도내압검사를 인후두 역류질환에 적용하였을 때 비 폐쇄성 연하장애 증상이 식도의 운동장애와 유의한 연관성을 보인다는 연구가 있었다. ${ }^{8)}$ 또 다른 연구에서는 고해상도 식도 내압검사 상 상부 식도 괄약근(upper esophageal sphincter) 의 기능 이상이 식도의 연동 운동장애와 연관성을 보여 인후 두 역류질환의 가능한 병인으로 제시되었다.' 하지만 인후두 역류질환에서 고해상도 식도내압검사를 이용한 식도 운동장 애의 임상적 중요성 및 상부 식도 괄약근의 기능과 연하장애 의 연관성에 대한 연구는 아직 많이 이루어지지 않았다. 이에 저자들은 인후두 역류질환에서 기존의 식도내압검사보다 우 수한 고해상도 식도내압검사를 적용하여 그 임상적 유용성 및 식도 운동장애 질환들과의 연관성을 알아보고자 하였다.

\section{대상 및 방법}

2010년 7월부터 2011년 7월까지 본원에서 역류증상지수(reflux symptom index) 13 이상과 역류소견점수(reflux finding score) 7 이상으로 인후두 역류질환으로 진단된 환자를 대 상으로 전향적으로 연구하였다. 진단된 환자들은 치료 시작 전 고해상도 식도내압검사를 시행하였으며, 치료는 생활습관 개선 및 양성자 펌프 억제제(Lanston LFDT, 30 mg, Takeda Pharm.
Korea, Seoul, Korea, 1일 1회)로 하였다. 후두암, 알레르기 비 염, 부비동염, 편도염, 폐질환, 경추 질환과 같이 검사에 영향을 미칠 수 있는 질환을 가지고 있거나, 검사에 영향을 미칠 수 있 는 약물을 복용하고 있던 환자는 대상에서 제외하였다. 본 연 구는 강북삼성병원 임상시험 심사위원회의 허가와 관리하에 진행되었다. 총 56 명의 환자가 본 연구에 포함되었으며, 전체 환자들의 평균나이는 51.4 세 남성은 20 명, 여성은 36 명이었다.

고해상도 식도내압검사는 The ManoScan 360TM HighResolution system(Sierra Scientific Instruments Inc., Los Angeles, CA, USA)을 사용하였다. 환자는 8시간 이상 금식 후 앉은 자세에서 채널당 12 개의 압력 감지 센서를 가지고 있는 36 개의 채널을 지닌 $4.2 \mathrm{~mm}$ 두께의 관을 코를 통하여 하인두 부터 위에 이르는 공간에 위치시킨 후 $10 \mathrm{~mL}$ 의 물을 20 초의 간격으로 15 회 삼킨 후 나타나는 식도내의 압력의 변화를 측 정하였다. 측정된 압력의 변화는 manoview analysis software(Sierra Scientific Instruments Inc., Los Angeles, CA, $\mathrm{USA}$ )를 사용하여 정량 분석하였으며, 식도운동의 이상은 Chicago classification ${ }^{10}$ 에 따라 normal, peristaltic dysfunction, diffuse esophageal spasm, relaxation impairment of lower esophageal sphincter(LES), achalasia, hypotensive LES, relaxation impairment of upper esophageal sphincter(UES), nutcracker esophagus, decreased resting pressure 등으로 분류했다(Fig. 1). 고해상도 식도내압검사를 시행하기 전 임상 증상에 대한 설문지 검사를 시행하였고, 환자가 주관적으로 느 끼는 증상의 불편함 정도를 없음, 경함, 중함, 심함으로 표기하 도록 하였다. 그 중 연하장애 증상에 경함, 중함, 심함으로 표 기한 환자를 연하장애가 있는 군으로 분류하여 증상이 없는 군과 고해상도 식도내압검사 결과의 차이를 비교 분석하였다.

통계학적 분석은 SPSS 18.0(IBM, Armonk, NY, USA)을 이 용하였고, Student t-test 및 Fisher-exact test를 통해 인자 들의 상호 연관성을 보았으며 $p$ 값이 0.05 미만일 때 통계적으 로 유의성이 있다고 정의하였다.

\section{결 과}

설문지 검사 상 여러 증상 중에서 목의 불편감을 호소한 환
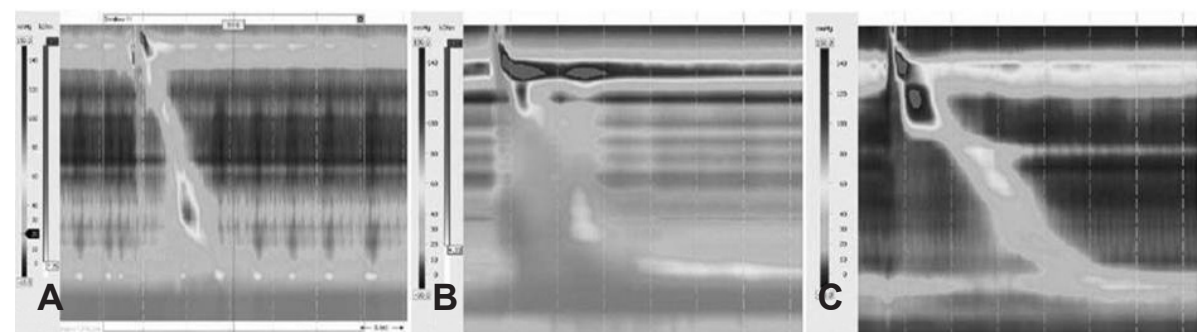

Fig. 1. High resolution manometry results shows pressure by color change. Time is presented on the X-axis, and distance from the nostril is presented on the Y-axis. Normal (A). Peristaltic dysfunction (B). Relaxation impairment of lower esophageal sphincter (C). 
자가 27명(48.2\%)으로 가장 많았으며, 그 다음으로 조기포만 감을 느낀 환자 26명(46.4\%), 상복부 통증 24명(42.8\%), 흥부 작열감 22명(39.3\%), 트림 22명(39.3\%), 역류 18명(32.1\%), 식욕 부진 17명(30.4\%), 애성 16명(28.6\%), 연하곤란 16명(28.6\%), 오심 11명(19.6\%), 되새김질을 호소한 환자가 10명(17.9\%), 마 른기침 9명(16.2\%)으로 나타났다(Table 1). 설문지 검사에서 연하장애를 호소한 16 명의 평균나이는 53.3 세, 남녀의 비율은 1 : 1.3, body mass index(BMI)는 평균 21.45였고, 연하장애 가 없는 군 40 명의 평균나이는 49.5세, 남녀 비는 $1: 2.1, \mathrm{BMI}$ 는 평균 22.3으로 두 군 간 통계학적인 유의한 차이는 없었다 (Table 2).

고해상도 식도내압검사 상 전체 환자 56명 중 30명(53.6\%) 의 환자에서 식도의 기능 이상소견을 보였다. 비정상적인 결과 는 peristaltic dysfunction이 11명(19.7\%)으로 가장 많았으며, 다음으로 relaxation impairment of LES 6명(10.7\%), diffuse esophageal spasm 4명(7.1\%), hypotensive LES 4명(7.1\%), nutcracker esophagus 3명(5.4\%), relaxation impairment of $\mathrm{UES} 2$ 명(3.6\%)이었다. 연하장애에 따른 결과의 차이는 증상 이 있는 환자군에서는 peristaltic dysfunction 4명(25\%), relaxation impairment of LES 4명(25\%), nutcracker esophagus 1명(6.3\%), hypotensive LES 1명(6.3\%), relaxation impairment of UES 1명(6.3\%)이었고, 증상이 없는 환자군에서
는 peristaltic dysfunction 7명(17.5\%)으로 가장 많았으며, 그 다음으로는 diffuse esophageal spasm 4명(10\%)이었다. 고해 상도 식도내압검사 상 확인된 식도 운동장애와 연하장애 증상 과는 통계적으로 유의한 연관관계를 보이지 않았다(Table 3).

전체 환자 56명의 고해상도 식도내압검사를 통한 상부 식 도 괄약근 검사 결과를 보면, 평균적인 위치는 외비공에서부터 $17.88 \pm 2.17 \mathrm{~cm}$ 이었고, 평균 기저 압력은 $63.10 \pm 24.49 \mathrm{~mm} \mathrm{Hg}$, 평균 잔압은 $1.20 \pm 7.58 \mathrm{~mm} \mathrm{Hg}$ 이었다. 연하장애가 없던 군에 서 상부 식도 괄약근의 이상을 보인 환자는 8 명으로 기저압이 감소된 환자가 4명으로 가장 많았고, 기저압이 상승된 환자는 2 명, 잔압이 증가된 환자가 2 명이었다. 연하장애가 동반된 군 에서 이상소견이 보인 환자는 4명으로 기저압이 감소된 환자 2 명, 잔압이 증가된 환자가 2 명이었다. 연하장애 유무와 측정 된 식도 상부괄약근 평균 값은 유의한 차이를 보이지 않았다 (Table 4).

\section{고 찰}

인후두 역류질환은 이비인후과 외래에서 접하는 가장 흔한 질환 중 하나로, ${ }^{211)}$ 환자가 호소하는 역류증상지수, 후두 내시 경상 보이는 역류소견점수, 양자 펌프 억제제를 이용한 경험적 치료, 24시간 이중탐침 산도검사, 식도내압검사, 임피던스 검

Table 1. Questionnaires result of laryngopharyngeal reflux disease patients

\begin{tabular}{|c|c|c|c|c|}
\hline & No (\%) & Mild (\%) & Moderate (\%) & Severe $(\%)$ \\
\hline Quality of life & $10(17.9)$ & $31(55.4)$ & $12(21.4)$ & $3(5.3)$ \\
\hline Early satiety & $30(53.6)$ & $19(33.9)$ & $7(12.5)$ & $0(0)$ \\
\hline Loss of appetite & $39(69.6)$ & $11(19.6)$ & $2(3.6)$ & $4(7.2)$ \\
\hline Throat discomfort & $29(51.8)$ & $20(35.7)$ & $6(10.7)$ & $1(1.8)$ \\
\hline Heartburn & $34(60.7)$ & $15(26.8)$ & $4(7.1)$ & $3(5.4)$ \\
\hline Epigastric pain & $32(57.2)$ & $20(35.7)$ & $4(7.1)$ & $0(0)$ \\
\hline Belching & $34(60.7)$ & $12(21.4)$ & $8(14.3)$ & $2(3.6)$ \\
\hline Reflux & $38(67.9)$ & $16(28.5)$ & $2(3.6)$ & $0(0)$ \\
\hline Nausea & $45(80.4)$ & $11(19.6)$ & $0(0)$ & $0(0)$ \\
\hline Dry cough & $47(83.8)$ & $5(9.0)$ & $2(3.6)$ & $2(3.6)$ \\
\hline Hoarseness & $40(71.4)$ & $10(17.9)$ & $6(10.7)$ & $0(0)$ \\
\hline Swallowing difficulty & $40(71.4)$ & $10(17.9)$ & $6(10.7)$ & $0(0)$ \\
\hline Repetitive swallowing & $46(82.1)$ & $7(12.5)$ & $3(5.4)$ & $0(0)$ \\
\hline
\end{tabular}

Table 2. Demographic data of the laryngopharyngeal reflux disease patients according to dysphagia symptom

\begin{tabular}{lccc}
\hline & Total $(\mathrm{n}=56)$ & LPRD without dysphagia $(\mathrm{n}=40)$ & LPRD with dysphagia $(\mathrm{n}=16)$ \\
\hline Age & 51.4 yrs $(17-74)$ & 49.5 yrs $(17-74)$ & 53.3 yrs $(28-73)$ \\
Sex $(\mathrm{M} / \mathrm{F})$ & $20 / 36$ & $13 / 27$ & $7 / 9$ \\
Height $(\mathrm{cm})$ & 162.50 & 162.97 & 161.31 \\
Weight $(\mathrm{kg})$ & 61.41 & 62.33 & 59.10 \\
BMl & 23.26 & 22.30 & 21.45 \\
\hline
\end{tabular}

LPRD: laryngopharyngeal reflux disease, BMI: body mass index 
Korean J Otorhinolaryngol-Head Neck Surg I 2013;56:637-41

Table 3. High resolution manometry results according to dysphagia symptom

\begin{tabular}{lccc}
\hline & Total $(\mathrm{n}=56)$ & LPRD without dysphagia $(\mathrm{n}=40)$ & LPRD with dysphagia $(\mathrm{n}=16)$ \\
\hline Normal & $26(46.4 \%)$ & $21(52.5 \%)$ & $5(31.3 \%)$ \\
Peristaltic dysfunction & $11(19.7 \%)$ & $7(17.5 \%)$ & $4(25 \%)$ \\
Hypertensive peristalsis (nutcracker) & $3(5.4 \%)$ & $2(5 \%)$ & $1(6.3 \%)$ \\
Diffuse esophageal spasm & $4(7.1 \%)$ & $4(10 \%)$ & $0(0 \%)$ \\
Abnormal tone of LES & $4(7.1 \%)$ & $3(7.5 \%)$ & $1(6.3 \%)$ \\
Abnormal LES relaxation & $6(10.7 \%)$ & $2(5 \%)$ & $4(25 \%)$ \\
Abnormal tone of UES & $2(3.6 \%)$ & $1(2.5 \%)$ & $1(6.3 \%)$
\end{tabular}

LES: lower esophageal sphincter, UES: upper esophageal sphincter, LPRD: laryngopharyngeal reflux disease

Table 4. High resolution manometry results of upper esophageal sphincter function according to dysphagia symptom

\begin{tabular}{lccc}
\hline & Total $(\mathrm{n}=56)$ & LPRD without dysphagia $(\mathrm{n}=40)$ & LPRD with dysphagia $(\mathrm{n}=16)$ \\
\hline Location of UES $(\mathrm{cm})$ & $17.88 \pm 2.17$ & $17.74 \pm 1.98$ & $19.01 \pm 2.02$ \\
Mean basal pressure $(\mathrm{mm} \mathrm{Hg})$ & $63.10 \pm 24.49$ & $63.30 \pm 23.78$ & $62.80 \pm 25.17$ \\
Mean residual pressure $(\mathrm{mm} \mathrm{Hg})$ & $1.20 \pm 7.58$ & $1.21 \pm 7.51$ & $1.20 \pm 7.55$ \\
Relaxation time to nadir $(\mathrm{ms})$ & $217.90 \pm 105.06$ & $218.51 \pm 104.76$ & $217.50 \pm 106.08$ \\
Relaxation duration $(\mathrm{ms})$ & $600.95 \pm 208.79$ & $601.04 \pm 209.01$ & $600.77 \pm 208.23$ \\
Recovery time (ms) & $382.61 \pm 176.99$ & $382.97 \pm 177.03$ & $381.85 \pm 176.71$ \\
\hline
\end{tabular}

UES: upper esophageal sphincter, LPRD: laryngopharyngeal reflux disease

사 등 다양한 검사들을 통하여 진단할 수 있다. ${ }^{12,13)}$ 하지만 인 후두 역류질환은 증상이 비특이적인 경우가 많고 내시경 소견 및 질병의 중증도가 서로 일치하지 않는 경우가 많으며 진단 및 치료와 관련하여 객관적이고 정확한 기준은 아직 제시되지 않 고 있다. ${ }^{14)}$

고해상도 식도내압검사의 지형분석은 Clouse와 Staiano ${ }^{6)}$ 에 의해 제시된 개념으로, 장비와 기술의 발전으로 진정한 의미의 고해상도 식도내압검사가 시작되었다. ${ }^{15)}$ 고해상도 식도내압검 사는 기존의 식도내압검사와 달리 정교한 측정이 가능하며, 환 자의 순응도가 높아 위식도 역류질환 환자의 검사에 있어 많 이 사용되고 있다. 또한 고해상도 식도내압검사는 상부 식도 괄 약근 및 하부 식도 괄약근이 정상적일 경우라도, 강직성 활동, 이완, 연동운동의 동조를 파악할 수 있어 유용하다. ${ }^{11}$

Carroll 등히는 양자 펌프 억제제 치료에 실패한 인후두 역 류질환 환자를 대상으로 고해상도 식도내압검사를 시행하여 전체 23명의 환자 중 8명(34.8\%)에서 이상을 보였고, 그 중 5 명은 연동 운동의 장애를, 1 명은 상부 식도 괄약근의 압력 증 가, 2 명은 하부 식도 괄약근의 압력이 감소된 소견을 보였다고 보고했다. Lee 등 ${ }^{17)}$ 저자들이 이전에 후향적으로 연구하여 보 고한 인후두 역류질환 환자에서 양자 펌프 억제제 치료 효과 에 따른 고해상도 식도내압검사 분석에 따르면 치료 효과에 따른 통계학적 차이를 보이지는 않았지만 전체 99명의 환자 중 $41.4 \%$ 에서 식도의 기능 이상을 확인하였다. Knight 등 ${ }^{18)}$ 은 인후두 역류질환 및 위식도 역류질환 환자에서 고해상도 식도 내압검사를 시행한 결과 $71 \%$ 의 환자에서 식도운동의 이상을
보였고, 그 중 식도 연동운동장애가 $48 \%$ 로 가장 흔하다고 보 고했다. 또한 Knight 등 ${ }^{18)}$ 은 식도 운동의 장애가 비전형적 위식 도 역류 및 인후두 역류질환과 유의한 연관성을 보인다고 하였 다. Jacob 등 ${ }^{19)}$ 의 연구에 따르면 식도 운동의 이상이 있는 환자 들은 식도 근위부에서 위산제거가 지연되며 자극을 받아 이물 감을 유발할 수 있다고 보고하였다. 본 연구에서도 약 $53.6 \%$ 의 환자에서 식도운동의 장애를 보였고, 식도운동의 장애를 보인 환자 중 연동 운동의 이상을 보인 경우가 11 명(19.7\%)으 로 가장 많았다. 이는 식도 운동장애가 인후두 역류질환의 병 인으로 가능성이 있음을 보여주는 결과라 생각된다.

Singh 등 ${ }^{8}$ 은 인두 이물감을 느끼는 위식도 역류질환 환자 에서 고해상도 식도내압검사를 통한 연구에서 연하장애와 식 도 운동장애가 유의한 연관이 있는 것으로 보고하였다. 본 연 구에서도 연하장애와 식도의 운동장애의 연관성을 확인하고 자 인후두 역류질환에서 증상에 따른 고해상도 식도내압검사 결과를 분석하였다. 하지만 기존보고와 달리 연하장애 증상 유 무에 따른 고해상도 식도내압검사의 이상 정도와 상부 식도 괄 약근 측정 결과는 통계적으로 유의한 차이를 보이지 않았다. Vardar 등 ${ }^{9}$ 의 인후두 역류질환 환자에서 상부 식도 괄약근 기 능을 연구한 보고에 따르면 66명의 환자 중 9명(13.6\%)의 환자 에서 상부 식도 괄약근의 이상이 관찰되었고, 만성적인 기침 과 상부 식도 괄약근의 이상이 유의한 상관관계를 보인다고 보 고하였다. Vardar 등흐는 상부 식도 괄약근 잔압은 인두에서 식 도로 배출시 저항을 나타내는 지표로 증가시 배출이 지연되며 만성기침과 연관이 있을 것으로 보고하였다. 본 연구에서 상 
부 식도 괄약근의 잔압 증가를 보인 환자는 4명(7.1\%)이었고, 연하곤란 증상과 유의한 차이를 보이지는 않았다. 이는 정상 군과의 비교가 아닌 연하장애 증상에 따라 분류한 같은 질병 군 사이의 비교 때문일 것으로 생각되며, 또한 본 연구에 포함 된 대상환자의 수가 적었기 때문에 추후 대규모 연구를 통한 확인이 필요할 것으로 생각된다.

\section{REFERENCES}

1) Kim YM. The management of laryngopharyngeal reflux disease. Korean J Otolaryngol-Head Neck Surg 2002;45(9):835-8.

2) Chung MK, Min JY, Oh JW, Jeong HS, Baek CH, Son YI. The efficacy of 4-week short-term therapy with proton pump inhibitor as an initial treatment regimen for the patients with laryngopharyngeal reflux. Korean J Otolaryngol-Head Neck Surg 2005;48(6):796-800.

3) Ahn CM, Kim MR, Chung DH. The comparative study on the efficacy of ranitidine and rabeprazole in reflux laryngitis. Korean J Otolaryngol-Head Neck Surg 2003;46(6):513-9.

4) Wo JM, Grist WJ, Gussack G, Delgaudio JM, Waring JP. Empiric trial of high-dose omeprazole in patients with posterior laryngitis: a prospective study. Am J Gastroenterol 1997;92(12):2160-5.

5) Axford SE, Sharp N, Ross PE, Pearson JP, Dettmar PW, Panetti M, et al. Cell biology of laryngeal epithelial defenses in health and disease: preliminary studies. Ann Otol Rhinol Laryngol 2001;110 (12):1099-108.

6) Clouse RE, Staiano A. Topography of the esophageal peristaltic pressure wave. Am J Physiol 1991;261(4 Pt 1):G677-84.

7) Tsutsui H, Manabe N, Uno M, Imamura H, Kamada T, Kusunoki H, et al. Esophageal motor dysfunction plays a key role in GERD with globus sensation--analysis of factors promoting resistance to PPI therapy. Scand J Gastroenterol 2012;47(8-9):893-9.

8) Singh S, Stein HJ, DeMeester TR, Hinder RA. Nonobstructive dysphagia in gastroesophageal reflux disease: a study with combined ambulatory $\mathrm{pH}$ and motility monitoring. Am J Gastroenterol 1992; 87(5):562-7.
9) Vardar R, Sweis R, Anggiansah A, Wong T, Fox MR. Upper esophageal sphincter and esophageal motility in patients with chronic cough and reflux: assessment by high-resolution manometry. Dis Esophagus 2013;26(3):219-25.

10) Bredenoord AJ, Fox M, Kahrilas PJ, Pandolfino JE, Schwizer W, Smout AJ, et al. Chicago classification criteria of esophageal motility disorders defined in high resolution esophageal pressure topography. Neurogastroenterol Motil 2012;24 Suppl 1:57-65.

11) Koufman JA. The otolaryngologic manifestations of gastroesophageal reflux disease (GERD): a clinical investigation of 225 patients using ambulatory 24-hour $\mathrm{pH}$ monitoring and an experimental investigation of the role of acid and pepsin in the development of laryngeal injury. Laryngoscope 1991;101(4 Pt 2 Suppl 53):1-78.

12) Jung YH, Chang DY, Jang JH, Jung EJ, Hah JH, Sung MW, et al. Reflux symptom index (RSI) and reflux finding score (RFS) of persons taking health checkup and their relationship with gastrofiberscopic findings. Korean J Otolaryngol 2007;50(5):431-7.

13) Postma GN, Belafsky PC, Aviv JE, Koufman JA. Laryngopharyngeal reflux testing. Ear Nose Throat J 2002;81(9 Suppl 2):14-8.

14) Koufman J, Sataloff RT, Toohill R. Laryngopharyngeal reflux: consensus conference report. J Voice 1996;10(3):215-6.

15) Ghosh SK, Pandolfino JE, Zhang Q, Jarosz A, Kahrilas PJ. Deglutitive upper esophageal sphincter relaxation: a study of 75 volunteer subjects using solid-state high-resolution manometry. Am J Physiol Gastrointest Liver Physiol 2006;291(3):G525-31.

16) Carroll TL, Fedore LW, Aldahlawi MM. pH Impedance and highresolution manometry in laryngopharyngeal reflux disease highdose proton pump inhibitor failures. Laryngoscope 2012;122(11): 2473-81.

17) Lee CH, Lee HS, Jin SM, Lee SH. Analysis of High-Resolution Manometry Results in LPRD Patients Who Do Not Response to PPI Medication. J Korean Soc Logoped Phoniatr 2012;23(1):43-7.

18) Knight RE, Wells JR, Parrish RS. Esophageal dysmotility as an important co-factor in extraesophageal manifestations of gastroesophageal reflux. Laryngoscope 2000;110(9):1462-6.

19) Jacob P, Kahrilas PJ, Herzon G. Proximal esophageal pH-metry in patients with 'reflux laryngitis'. Gastroenterology 1991;100(2):30510. 